\title{
LOS PRINCIPIOS DE OLYMPE DE GOUGES: CULMINACIÓN DE UNA IDEOLOGÍA "REVOLUCIONARIA"
}

\author{
OLYMPE DE GOUGES'PRINCIPLES: CULMINATION OF A “REVOLUCIONARY” \\ IDEOLOGY
}

María Teresa Arias Bautista

Universidad Complutense de Madrid

\section{RESUMEN:}

Ante consignas revolucionarias como "ya no hay privilegios", o "todos los franceses son iguales", cabría cuestionarse si en ellas se incluía a las mujeres. Además, y en cualquier caso, ¿cuál fue la ideología respecto a ellas?, ¿cómo participaron en los acontecimientos?, $\mathrm{y}$, finalmente, ¿en qué quedaron los principios enunciados por Olympe de Gouges, mujer que captó los deseos, sueños y aspiraciones de sus contemporáneas y los legó a la posteridad a través de la conocida "Declaración de los derechos de la mujer y la ciudadana"?

\section{Palabras claves:}

Ideología revolucionaria, Olympe de Gouges, mujer, revolución..

\section{Abstract:}

In front of revolutionary slogans as "already there are no privileges", or "all Frenchmen are equal", it would be necessary to question if they included women. Moreover, and in any case, which was the ideology with regard to them? how they took part in the events?, and, finally, what were the principles enunciated by Olympe de Gouges, the woman who caught the desires, dreams and aspirations of other contemporary women and bequeathed to posterity by the famous "Declaration of the Rights of Woman and Citizen"?

\section{KEY WORD:}

Revolutionary ideology, Olympe de Gouges, woman, Revolution. 


\section{La Historia y las mujeres de la Revolución Francesa}

Muchos son los autores de la etapa post-revolucionaria que brindan noticias sobre la toma de conciencia política de las francesas. El historiador liberal y racionalista Jules Michelet, por ejemplo, declara en “Les femmes de la Revolution” que las mujeres estuvieron en la vanguardia de los acontecimientos (Duhet, 1974). Una simple mirada a los títulos de los capítulos que integran dicha obra confirma este extremo ${ }^{1}$. En ellos realiza un repaso exhaustivo tanto de la actividad individual como colectiva de las mujeres, sus propuestas, sus logros y sus esperanzas. La actitud femenina le parecía el cambio más radical de aquellos tiempos ${ }^{2}$ y la justificaba porque, según él, nadie podía estar más interesado en los asuntos públicos que quienes entregaban a sus hijos a la causa ${ }^{3}$.

Desde su perspectiva de gentilhombre y legitimista católico, el también historiador Alexis de Tocqueville no pudo sustraerse a significar el cambio ideológico femenino ${ }^{4}$ con independencia de sus planteamientos con respecto a la posición que debían ocupar en el mundo las mujeres. La igualdad de los sexos, pregonada por algunos teóricos, era para él un absurdo ya que "dicha situación degradaría a ambos sexos, pues sus funciones y deberes son distintos" (Márquez, 2010). Por su parte, Alphonse de Lamartine, escritor, poeta y político, facilita abundante información acerca de las actividades de las mujeres en la etapa revolucionaria, comenzando con la marcha que efectuaron sobre Versalles a instancias de Mirabeau, quien había predicho: "si las mujeres no se meten en ella no podrá hacerse nada". Sin embargo, para Lamartine,

1 Los capítulos a que hago referencia tienen los epígrafes siguientes: A las mujeres, a las madres, a las hijas; Influencia de las mujeres en el siglo XVIII; El heroísmo y la piedad: una mujer destruye la Bastilla; El amor y el amor de la idea; las mujeres del 6 de octubre, las mujeres de la federación las damas jacobinas, el palacio real en 90, emancipación de las mujeres; los salones-Mme. Staël; los salones-Mme.de Condorcet; Sociedades de mujeres: Olympe de Gouges y Rose Lacombe; Théroigne de Méricourt; Mme. Roland; Mmlle. Kéralio; Charlotte Corday; El palacio real, los salones; La primera mujer de Danton; la segunda mujer de Danton; La diosa razón, el culto a las mujeres por Robespièrre Lucile Desmoulins; Ejecución de mujeres, ipueden ser ejecutadas las mujeres?; Cathérine Théot Mére de Dieu; Le dame Saint-Amaranthe; Indiferencia hacia la vida; Cada partida perdida por las mujeres; La reacción de las mujeres en el medio siglo que siguió a la revolución; Conclusiones.

2 “Les mœurs changent-elles alors? Non, mais l'amour a pris son vol vers les plus hautes pensées. La patrie, la liberté, le bonheur du genre humain, ont envahi les cœurs des femmes" (Michelet, 1854).

3 “Oui, je disais aux femmes: Personne plus que vous n'est intéressé dans l'État, puisque personne ne porte plus que vous le poids des malheurs publics. L'homme donne sa vie et sa soeur. Vous donnez vos enfants" (Michelet, 1854)

4 "...también las mujeres, en medio de los menudos cuidados de la casa pensaban en esos grandes problemas de la existencia... El pensamiento ilustrado andaba por doquier, los señores y las damas pedían consejo... Las madres de familia se apresuraron a poner sus libros en manos de sus hijos..." (Tocqueville, 1973). aquellas acciones estuvieron plagadas de excesos ${ }^{5}$. Refiere la existencia de clubes femeninos organizados donde se debatían los más diversos asuntos y se proponían cambios en defensa de los intereses del colectivo y de los intereses sociales. Narra el comportamiento despreciable de calceteras y mercenarias, la importancia de los salones de las grandes aristócratas y las vicisitudes por las que deambuló la vida de algunas lideresas revolucionarias: Rosa Lacombe, Theroigne de Mericourt, Carlota Corday, Mme. Rolland, etc. Conforme a sus ideales, hace apología de las mujeres de las Sociedades Fraternales "por ocuparse con decoro de las cuestiones sociales análogas a su sexo", y por ello las considera "las filósofas de su sexo", y arremete contra las que formaban parte de la Sociedad Revolucionaria, a las que asigna oscuras procedencias, $\mathrm{y}$ actos, consignas y pretensiones tan absurdas como fuera de tono y lugar'.

La obra del abogado Lairtullier apunta, igualmente, interesantes puntos de vista sobre algunas dirigentes del movimiento revolucionario, $\mathrm{y}$, como el resto de autores, carga las tintas contra la participación en la vida revolucionaria de las extremistas del movimiento ${ }^{7}$. Todas estas opiniones, junto a las evidentísimas pruebas que nos han legado las propias mujeres revolucionarias, como los "Cuadernos de Quejas", los proyectos legislativos, los documentos emanados de la Asamblea, la prensa, o los

5 “Les femmes du peuple avant été les premières à aplaudir au dèvergondage d'Hébert. Mirabeau les avait suscitées d'un mot prononcé à Versailles, la veille des journèes de 5 et 6 octobre: 'Si les femmes ne s'ent mêlent', avait-il dit à demi-voix aux émissaires de l'insurrection parisienne, 'il n'y aura rien de fait'. Il savait que la fureur des femmes, une fois inflamée, s'élève à des accès et a des profanations que depassent l'audace des hommes. L'inspiration Antique, cette fuerur sacrée, bollonnat sur tout dans les sibylles. Les demagos savaient de plus que les baionnetes s'émoussent devant des pooitrines des femmes, et que se sont des mains san armes que désarment le mieux les soldat. Les femmes de Paris accourues à la tête des bandes de la capitale, avaient en effet violè les premières le palais du ri, brandi le poignard sur le lit de la reine, et rapportè à Paris, au bout de leus piques, les têtes des gardes du corps massacres. Théroigne de Mericourt et ses bandes avaient marchè à l'assault des Tuileries le 20 juin et le 10 aôt. Terrible pendant le combat, cruelles avec la victoire, elles avaient assassiné les vaincu, mutilè les cadavres, égouté le sang..." (Lamartine, 1847).

6 "La Societé Fraternelle de femmes tenant ses séances dans une salle attenante à la Salle des Jacobins. Cette reunión était composée de femmes lettrées que discutaient avec plus de décence les question sociales analogues à leur sexe, telle que le mariage, la maternité, l'éducations des enfants, les instutitions de secours et de soulagements à l'humanité. Elles étaient les philosophes de leur sexe... La société Revolutionnaire siégeant à Saint-Eustache...Elle étaient composée de femmes perdues, aventurières de leur sexe, recrutèe dans le vice, ou dans les réduits de la misére, ou dans les cabanon de la demance. Le scandale de leurs séanse, le tumultte de leurs motion, l'audace de leurs petition importunaient le Comitè de Salut Public..." (Lamartine, 1847).

7 "Unas mujeres dadas, de cuerpo y alma, al instrumento del suplicio, aumentando su atrocidad con sus endemoniadas vociferaciones, arrojando siniestros sarcasmos a la sangre que va pronto correr y sardónicas carcajadas a la vida que va pronto a acabar... Esas mujeres fueron jóvenes, tal vez hermosas, y susceptibles de amor; pero ya estas cualidades han sido brutalmente postergadas con el impuro contacto del mundo... La idea de hacer intervenir a las mujeres por ente el movimiento popular y el remolino demagógico, salió de una cabeza que solía producir rayos de luz...dijo Mirabeau en un gabinete de lectura de Versalles que no era posible la insurrección si las mujeres no se mezclaban en ella y se ponían a su cabeza: cuya especie fue vertida sin duda para que se difundiese y transportase a parís, como así sucedió. Maillard mandó proceder a una especie de reclutamiento de mujeres y lo demás ya es sabido. He aquí el origen de la intervención de las mujeres y de la parte activa que tuvieron en las tremendas escenas que tuvieron lugar" (Lairtullier, 1844). 
encendidos discursos de algunas de sus más combativas protagonistas, empeñadas en cambiar el curso de la historia, no hacen sino confirmar el hecho de que las mujeres se volcaron en la vida pública en cuanto vieron la posibilidad de hacerlo ${ }^{8}$, por más que no haya sido reconocido y valorado dicho esfuerzo durante muchos años, se haya silenciado o, en el peor de los casos, se haya considerado pernicioso y portador del caos.

En efecto, tan innumerables testimonios quedaron arrumbados tras las cortinas del teatro de la historia hasta la intervención de la historiografía feminista, momento en que comenzaron a recuperarse las hazañas colectivas e individuales de las mujeres de todos los tiempos (Duhet, 1974). Las mujeres que compartieron los fervores revolucionarios con sus conciudadanos varones emergieron para ser admiradas, pero, también, para ser denostadas por el pensamiento antifeminista. Como el de Lenotre, quien en su obra "La petite histoire. La revolution par ceux qui l'ont vue" realiza una ácida y destructiva crítica de las acciones femeninas durante la revolución, como si nunca hubiesen sabido ocupar su lugar, como si su presencia solo hubiese servido de escándalo, y nada, salvo la degradación y el deshonor, hubiesen arrastrado con ellas9. Las mujeres denostadas reiteradamente con el calificativo de "viragos"10 no merecían sino el abandono inmediato. Para Lenotre, aquéllas que, como Etta Palm, eran aclamadas como liberadoras por las ciudadanas, lo eran porque "las mujeres aceptaban fácilmente las nuevas ideas por su ignorancia; las expandían con facilidad

8 "...después de varios siglos de envilecimiento y esclavitud; debemos ponernos hoy a la altura de tal destino favorable que está reservado a uno y otro sexo. No basta con formar tácitamente nuestros corazones un voto de adhesión a los sublimes trabajos de los augustos representantes de la Nación Francesa; debemos contemplar como el primero y más sagrado de nuestros deberes, el hecho de manifestar exteriormente nuestras virtudes cívicas y pronunciar solemnemente nuestro juramento de fidelidad a la Constitución, el 14 de este mes, época feliz de la conquista de la Libertad". Deliberación de las damas ciudadanas del distrito de San Martín" (Alonso, I., y Belinchón, M., 1989).

9 "En la sociedad Popular de Coutanne las ciudadanas se encontraban relegadas en una tribuna, pero ellas descendían frecuentemente a la sala para abrazar al orador, por lo que los maridos decidieron protestar estas manifestaciones ya que la patria no ganaba nada y la moral podía perder... Algunos ciudadanos tomaron el hábito de sentarse en la tribuna de las damas; los maridos hicieron decretar que dicha tribuna permaneciera siempre alumbrada... Una 'virago' armada con un gran sable, estaba sentada permanentemente al lado derecho del presidente, recibía de cada nuevo miembro que entraba en la sala un abrazo. Es de señalar que tenía cuidado de sonarse los mocos con los dedos y limpiarse con la manga de su traje antes de recibir el fraternal abrazo" (Lenotre, 1934)

10 Es recurrente en esta etapa el uso en los textos del calificativo de viragos, mujeres viriles, hombres, que hacen referencia a las mujeres revolucionarias. Esto no es una novedad y puede detectars en textos de etapas históricas precedentes y sucesivas. Usada por los varones, estas fórmulas han servido, en todos los contextos, para denostar a las mujeres de quienes se hablaba. Se apelaba con ello a la falta de femineidad, a la transgresión de su sexo-género que les arrebataba crédito y fiabilidad. Sin embargo, es interesante señalar que las mujeres también se lo aplicaban a ellas mismas en sus escritos o discursos. Buscaban tanto asociarse con cualidades o acciones que ellas reivindicaban ("Que importa el sexo, todo lo hace el alma"), como identificarse con la calidad de ser humano, con su esencia, predicada únicamente del hombre. De ahí que en numerosas ocasiones, Olympe de Gouges se refiera a si misma como "un hombre" y niegue tal categoría a algunos varones de su entorno, entre ellos a Robespierre. porque eran ligeras y las sostenían durante tiempo porque eran cabezotas." (Lenotre, 1934). Tras relatar historias y situaciones que concitan al desprestigio de personas y actuaciones, termina su presentación de las que él llama "feministas" citando las palabras de Napoleón sobre el particular: "hay solo una cosa que no es francesa, que una mujer pueda hacer lo que le apetezca", y añade: “iAh! este no fue nunca feminista" (Lenotre, 1934).

Finalmente, el redescubrimiento de los valores revolucionarios femeninos se consolida de la mano de la conmemoración del II Centenario de la Revolución, en 1989. En su estela proliferaron obras que recogieron las biografías y memorias de mujeres importantes de la Revolución, colecciones documentales a ellas debidas, y obras de conjunto en que se trataba explícitamente el tema. En todos estos trabajos las mujeres aparecen volcadas en cualquier actividad pública a su alcance, ocupando espacios inesperados. Estaban dispuestas a no dejar pasar la oportunidad que les brindaba un momento histórico excepcional: crearon asociaciones, elaboraron proclamas, encabezaron manifestaciones, hablaron en las tribunas para reclamar derechos, usaron hábilmente la pluma en sus quejas y reivindicaciones, defendieron barricadas e incluso lucharon cuerpo a cuerpo en la vanguardia del enfrentamiento armado ${ }^{11}$. Pero, ¿cuáles fueron las bases teóricas que facilitaron estas actuaciones?

\section{LA IDEOLOGÍa REVOLUCIONARIA Y LAS MUJERES}

Es bien sabido que las raíces ideológicas de la Revolución se hunden en la Ilustración, cuyos postulados resume magníficamente Tocqueville ${ }^{12}$. Una concepción nueva del mundo y del hombre se extendió por toda Europa proclamando el progreso de la modernidad con la ambición de hacerlo extensivo a todo el orbe. Naturaleza derechos del hombre, razón y ciencia fueron los postulados ilustrados. Se ha dicho que "la Ilustración es anti-histórica y sueña con un hombre ideal y universal en el que la naturaleza y la razón constituyen las supremas normas de valor en todo el ámbito humano", y que la consigna del ilustrado era "difundid la luz de la razón, que la virtud y la dicha juntarán por sí mismas sus manos" (Hirschberger, 1978). Todo era válido en aras de la razón y del progreso y se difundió a través de "La Enciclopedia",

11 “Atan cuerdas a las cureñas de los cañones, pero al tratarse de cureñas de cañones de barco, dicha artillería es de dificultoso desplazamiento. Entonces las mujeres requisan carruajes, cargan en estos sus cañones y los amarran con cables, cargan asimismo pólvora y balas de cañón; unas guían los caballos, otras, sentadas sobre los cañones, llevan en la mano la terrible mecha y otros instrumento de muerte. Al iniciar su marcha sobre los Campos Elíseos, su número ya sobrepasa las 4.000, y van escoltadas por 400 o 500 hombres, que se habían armado con todo cuanto habían podido encontrar (Alonso, I., y Belinchón, M., 1989).

12 “La idea de la grandeza del hombre en general, de la omnipotencia de su corazón, de la extensión ilimitada de sus luces, había calado los espiritus y los embargaba; a esta soberbia noción de la humanidad, en general, se mezclaba un desprecio contra natura por la época en que se vivía y por la sociedad de la que se formaba parte" (Tocqueville, 1973). 
publicada entre los años 1751 y 1772 por D'Alembert y Diderot bajo los auspicios de Mme. Pompadour y Malesherbes. Fue la obra magna del Siglo de las Luces y su fin no era otro que "por sus enseñanzas, llevar la felicidad a todos los rincones, al mismo tiempo que luchar contra el oscurantismo, la intolerancia y los prejuicios" (Puleo, 1993).

En la Enciclopedia, donde se discurrió sobre todos y cada uno de los temas del ingenio y la obra humana, la mujer fue analizada bajo tres perspectivas diferentes: el derecho natural, la antropología y la moral. Los dos primeros artículos avanzan ideas igualitarias, el tercero comparte el ideal roussoniano de sometimiento que, a la larga, será el triunfador. La exposición basada en el derecho natural fue obra de Jaucourt. Parte de la tradición veterotestamentaria y de los diversos códigos legislativos existentes. Pone de manifiesto que el matrimonio, teóricamente un acuerdo voluntario, genera la sumisión de la mujer al marido como si de su amo se tratase. De tal situación generalizada pudiera parecer que la mujer acepta ese dominio, lo que Jaucourt considera refutable por la dificultad de demostrar que la autoridad del marido proviene de la naturaleza, idea que iría en contra de los principios ilustrados de la igualdad natural; por la constatación de que no siempre el hombre tiene mayor fuerza, cordura, inteligencia y mejor conducta que la mujer y, finalmente, por el hecho indiscutible de que si el matrimonio es un convenio entre partes, nada impide cambiarlo. Tras esto el autor alega que la mujer era capaz de gobernar la familia puesto que había sido capaz de gobernar imperios (Puleo, 1993).

El abate Mallet realiza el comentario desde el punto de vista de la antropología. En él afirma que los diversos prejuicios sobre la relación de excelencia del hombre respecto a la mujer han sido producidos por las costumbres de los pueblos antiguos, los sistemas políticos y las religiones. También señala que es sorprendente el gran número de mujeres destacadas por su erudición y sus obras, a pesar de haberse descuidado tradicionalmente la educación de las mujeres (Puleo, 1993).

El texto sobre la mujer elaborado desde el punto de vista de la moral lo suscribe Desmahis y en él se elucubra sobre la inferioridad femenina. El autor hace un alegato sobre las "gracias físicas", carencias intelectuales y morales que acompañan a dicho sexo y, por todo ello, determina la necesidad casi imperiosa que tiene la mujer de convertirse, para ser digna y respetable, en madre de familia dulce, sumisa y silenciosa (Puleo, 1993). Obviamente, estas posturas no hacen sino evidenciar la polémica ilustrada sobre los sexos, una más de las pulsiones de la conocida "Querelle des femmes", de rastro tan anterior como ulterior y sinuoso. En esta etapa, como en los anteriores y posteriores, la inquietud generada por la causa femenina dividió a preclaros varones que se cuestionaban la injusticia de su dominación o probaban la misma, aunque también hubo quienes, como Montesquieu, no comprometieron sus opiniones. Dos de los opuestos representantes en este dialéctica fueron D'Alembert y Rousseau.
El pensamiento del primero, expuesto en una carta dirigida al ginebrino, refleja un sincero sentimiento de culpa por la opresión que, a su entender, en todas partes había sufrido el género femenino ${ }^{13}$.

Rousseau, amante del progreso, la libertad y el bien de la humanidad, parte de perspectivas bien diferentes. En él el sentimiento lo es todo y, en consecuencia, se sitúa frente al racionalismo de los ilustrados (Hirschberger, 1978). Para nuestro análisis interesa, especialmente, su tratado sobre la educación conocido por "El Emilio" (Rousseau, 1973). En él establece las pautas de enseñanza de los niños para forjar hombres libres. Solo dedica a la formación de las niñas un capítulo, el quinto, y lo titula "Sofía", nombre de la mujer destinada a ser la esposa de Emilio. Sus razonamientos siguen la arcaica tradición de subordinación femenina. Rousseau afirma que en la unión de los sexos existe la primera diferencia notable: "el uno debe ser activo y fuerte y el otro pasivo y débil". Quizá en este "deber ser" se apunta la necesidad de lo deseable más que de lo real; un hecho que, a fuerza de imponerlo, quedará determinado como tal. Rousseau afirma que de la desigualdad de los sexos nacen las diferencias de sus deberes. Para él, como para una ingente mayoría de intelectuales de su época, la maternidad marca indefectiblemente la diferencia, tal y como había venido proclamándose siglo tras siglo y como vendrá haciéndose con posterioridad ${ }^{14}$ En consecuencia, su educación deberá limitarse a lo conveniente ${ }^{15}$. La incapacidad para tomar sus propias decisiones llegará al límite de negarles el derecho a elegir sus propias creencias ${ }^{16}$. Aunque estos no son sino unos breves trazos sobre el estado del pensamiento en torno a las mujeres en los momentos pre-revolucionarios, sirven para mostrar en qué ideas se apoyaron las mujeres y contra cuáles se rebelaron. La Ilustración

13 “La esclavitud y la degradación a que hemos reducidos a las mujeres, las trabas que ponemo a su intelecto y a su corazón, la jerga fútil y humillante para ellas y para nosotros a la que hemo reducido nuestra relación con ellas, como si no tuvieran una razón que cultivar o no fueran dignas de ello. La educación funesta, yo diría casi homicida que les prescribimos, sin permitirles tener otra la educación en la que aprenden casi únicamente a fingir sin cesar, a ahogar todos los sentimientos, a ocultar todas sus opiniones y disfrazar todos sus pensamientos. Nos comportamos con su naturalez como lo hacemos con la de nuestros jardines, tratamos de adornarla sofocándola. Si la mayoría de las naciones ha actuado como nosotros al respecto, es porque los hombres siempre han sido los más fuertes en todas partes y porque en todas partes el más fuerte es el opresor del más débil..." (Puleo 1993).

14 "Sostener de manera vaga que son iguales los dos sexos y que tienen unas mismas obligaciones, es perderse en manifestaciones vanas... Decís que no están siempre embarazadas. No, pero su destino es estarlo" (Rousseau, 1973)

15 “Deben aprender muchas cosas, pero sólo las que conviene que sepan... Su educación debe estar en relación con la de los hombres, agradarles, serles útiles, hacerse amar y honrar de ellos, educarlos cuando niños, cuidarlos cuando mayores, aconsejarlos, consolarlos, hacerles grata y suave la vida, son las obligaciones de las mujeres en todos los tiempos, y esto es lo que desde su niñez se les debe enseñar" (Rousseau, 1973)

16 "Toda muchacha debe tener la religión de su madre, y toda casada la de su marido. Aun cuando esta religión fuera falsa, la docilidad que sujeta a la madre y a la hija el orden de la naturaleza borra para con Dios el pecado del error. No hallándose en estado de ser jueces por sí mismas, deben aceptar la decisión de sus padres y de su marido como de la Iglesia" (Rousseau, 1973). 
les hizo verse a sí mismas como seres humanos completos y la Revolución les ofreció la oportunidad de demostrar que no eran niñas, sino ciudadanas de pleno derecho. Les permitió poner en práctica los cánticos de igualdad y, abandonando el espacio doméstico, ocupar la calle, la prensa, la tribuna de oradores... Sin embargo, aunque las abanderadas del movimiento femenino llegaran a rozar con los dedos tan ansiadas expectativas, pospuestas generación tras generación, cuando se planteó la necesidad de cristalizarlas y dar consistencia legal a la realidad que se vivía, todo se desplomó como un castillo de naipes. Las mujeres exigieron una amplia participación de pleno derecho, exigieron el derecho al voto. Entonces, hasta los varones más progresistas se espantaron con la idea de conferirles poder y decidieron hacerlas volver a la oscuridad de los fogones. La defensa de los valores tradicionales de la familia, el recato, el honor, el pudor y la maternidad, entre otros, fueron los argumentos esgrimidos por los padres de la patria francesa del momento ${ }^{17}$. La ley Napoleónica dará el golpe de gracia a todas las pretensiones con las que soñaron las mujeres en aquellos días y en los venideros ${ }^{18}$.

Ante los truncados resultados de aquella lucha, se perfila una nueva pregunta: ¿El reconocimiento de la felicidad para todos, meta de los postulados revolucionarios, incluía a las mujeres? La respuesta es sencilla: sí, pero como declaraba Talleyrand en 1791, “con la condición de que ellas no aspiren al ejercicio de los derechos y las funciones políticas" (Sledziewski, 1993). El argumento: el orden de la naturaleza roussoniano presentado como verdad incuestionable e inmutable. Cuando la Revolución se hubo cimentado, la mujer cívica, como afirma Sledziewski, quedó transformada en ciudadana, pero ciudadana de segunda categoría, tal y como se dictó en los cuadernos de la Asamblea Constituyente, los días 10 a 19 de septiembre de $1791^{19}$. La cínica maniobra, que primero utilizó la fuerza femenina para después relegarla, no escapó a algunas personalidades comprometidas con el futuro. Varias voces se alzaron contra

17 “Chaumette...femmes imprudents, qui voulez devenir hommes...Ces femmes perverses qui on Roland, qui se crut capable de gouverner la nation et qui courrut à se perte... Amar, provoqué par Robespierre, prit la parole à ce sujet à la Convention: Je vous dénonce, dit-il, un rensemblement de plus de six mil femmes, soi-disant Jacobines et membres d'une prétendue Société Revolurionaire. La nature, para la difference de forme et de conformation, leur à donné d'autres devou. La pudeur qui leur interdit la publicité, leur fait une loi de rester dans l'interieur de la famille. La Convention adopte ces príncipes et ferme les clubs de femmes" (Lamartine, 1847).

18 No es lugar para enumerar los artículos de la ley en que se recortan los derechos y libertades que las mujeres pensaron haber obtenido con la Revolución. Basta echar un vistazo al código napoleónico para percatarse de los mismos

19 "las ciudadanas deben ser instruidas bajo el imperio de la libertad y la igualdad... en el momento en que ellas renuncien a todo derecho político, adquieren la certeza de ver afirmarse, y hasta acrecentarse, sus derechos civiles" (Sledzieewski, 1993). aquellas promesas de libertad e igualdad cercenadas para el sexo femenino, entre ellas: Olympe de Gouges, Mary Wollstoncraft, y Condorcet ${ }^{20}$.

\section{Vida Y PRINCIPIOS de Olympe de Gouges}

La biografía de esta mujer no es muy amplia, como sucede con casi todas las revolucionarias famosas. Nació en Montauban, el 7 de mayo de 1748. Su origen es un tanto oscuro, quizá por el propio interés de Olympe de crearse un halo de misterio para ocultar sus humildes orígenes (Duhet, 1974). Unos la hacen hija de una familia de carniceros, otros, la mayoría, estiman que fue el fruto de una relación pasajera entre una comerciante de tejidos llamada Olympe Mouisset y un tal Jean-Jacques Lefranc de Pompignan. En su época hubo infundados rumores de que era hija natural de Luis XV (Michelet, 1854).

A la edad de 16 años ya era viuda de un tal Louis ó Pierre Auby (ambos nombres figuran en las biografías), oficial de Intendencia. Tenía un hijo, y un caudal, nada desdeñable, de unos sesenta mil francos, con los que "llegó a Paris en la flor de la edad, rebosando toda de imaginación y atractivos" ${ }^{\prime 21}$. Testimonios de la época afirmaban que Olympe no sabía leer ni escribir. Pero, como en otros casos de mujeres que destacaron por su pluma y a las que se ha negado el conocimiento, esta afirmación debe cuestionarse. Máxime, si atendemos a la campaña de desprestigio desatada contra ella, que acabó con su ejecución como enemiga pública. En sus escritos manifiesta un acervo cultural que no encaja con la ignorancia y habla, sin embargo, de una preparación más elevada que la media, no solo de las mujeres, sino de la mayoría de los varones contemporáneos. El uso de secretarios, que sirve para afirmar su falta de capacidades, tal vez pudiera deberse a la rapidez con que fluían sus ideas. Sea como fuere, pronto llegó a ser conocida en los círculos de la Comédie Française. Compuso alrededor de 30 obras $^{22}$ que logró representar, por sus buenas relaciones. La primera "Zamor y Thirza, o el feliz naufragio" obtuvo un gran éxito en 1789. En "La esclavitud de los

20 "Cada uno de ellos fijaron sus alegatos en un plano diferente: político, ético y filosófico, respectivamente. Condorcet se basó en el status jurídico de la mujer, Gouges en su papel político y Wollstronecrafft, en su ser social. Los tres están de acuerdo en la urgencia de una formulación y Wollstronecraftt, en su ser social. Los tres estan de acuerdo en la urgencia de una formulación explicita de los derechos de la mujer, pero, estos no tienen en absoluto el mismo sentido para los perjudicial a la geometría constitucional, Olympe ve el objeto de una movilización histórica de las mujeres, mientras Mary, ve una oportunidad para la mutación. El punto de Vista de Condorcet es mujeres, mientras yary, ve una oportunidad para la mutación. El punto de militante y, Mary se centra en la dimensión cultural. Estos tres enfoques pueden ser distinguidos aún en el debate sobre los derechos de la mujer" (Sledzieewski, 1993).

21 Datos que suministra Lairtullier, a quien seguiré especialmente porque es quien facilita la mayor información sobre la vida de Olympe y quien analiza la mayor parte de sus creaciones literarias. 22 Michelet la compara con Lope de Vega (Michelet, 1854). Lairtullier enumera todas y cada una de ellas al final de su biografía (Lairtullier, 1844). 
negros" se vieron plasmados sus sentimientos revolucionarios que clamaban contra tan deleznable explotación.

Su compromiso social es más visible en los innumerables folletos que sucedieron a las obras literarias, entre las que también se cuentan dos novelas. Asiduamente, además, escribía en el periódico "L'Impatient", que llegó a dirigir. Recibió muchas críticas, algunas especialmente duras, como la de los autores del "Pequeño almanaque de las grandes mujeres", que ponían en duda su capacidad para componer un drama en 24 horas sobre cualquier asunto que se le propusiese, tal y como había apostado. Lairtullier refiere que su vida literaria fue "una serie de disgustos y contratiempos, mezclados con cortísimos instantes de gloria", pero que en sus composiciones "se anotan conceptos muy ingeniosos y a veces gérmenes de felicísimas ideas". A decir del autor citado, Olympe era una mujer necesitada del elogio y la admiración popular ${ }^{23}$, por lo que buscó gozar de ellos en la carrera dramática, después sustituidos por los que halló en "su nuevo destino" público, según ella misma confiesa: “QQué porvenir tan brillante se presenta para un pecho animado de cívico ardor! Ansío lanzarme en la carrera de los proyectos de utilidad nacional y abandonando comisiones, enredos, papeles, comedias, actores y actrices, no veo ya sino planes de pública felicidad".

Este exultante afán de acercarse a la política es juzgado por Lairtullier de la siguiente forma: "Supuesto que se acababa de proclamar el principio de igualdad ante la ley, sin límites, ni excepción, juzgó ella que también podrían las mujeres tomar parte activa en la gran discusión de los intereses generales, y se dijo a sí misma: ¡Yo también pelearé con voz y pluma!". Sus convicciones políticas eran moderadas y próximas a las opiniones girondinas, aunque a veces fue tachada de ultra republicana y otras de fanática realista o vendida al gobierno. Admiradora de La Fayette, inicialmente se inclinó por una monarquía constitucional, según dejó entrever en la columna titulada "El grito del sabio", dónde negaba al Tercer Estado el derecho a legislar por sí solo. Cambió rotundamente, haciéndose republicana, desilusionada por la huida del rey. Sus palabras manifiestan una especie de conversión milagrosa ${ }^{24}$. A partir de este momento se multiplicó su actividad arropada por una gran capacidad de trabajo y una

23 “...es la explosión, el desenfreno y la provocación personificada... totalmente excéntrica, tiene necesidad de sobresaltar, de pasmar, de obrar sobre las masas con el estallido de su voz, el calor y la fogosidad de sus discursos, la magia y el entusiasmo y la rapidez de las emociones, os obliga a tragaros indistintamente las frases más bárbaras y los conceptos más informes, a la par con periódicos sobresalientes y páginas llenas de interés" (Lairtullier, 1841).

24 “La luz hirió de repente mi vista, y, más que brillante, permanecí mucho tiempo en tal confusión de ideas, que en un principio me vi imposibilitada de pronunciar mi opinión, más pronto se disiparon las tinieblas, llegó el resplandor del día y sentí que yo era y moriría libre. iLibre, conciudadanos pero para servir a mi patria e idolatrarla hasta el último suspiro! ¡Qué hermoso es servir a la causa del pueblo y morir por ella!" (Lairtullier, 1841). militancia comprometida. Fruto de ellas fue la fundación del primer club de mujeres ${ }^{25}$. "Sociedad popular de mujeres" ${ }^{26}$. En sus tribunas y en otras muchas más, incluso en las nacionales, la explosiva personalidad de Olympe le hicieron destacarse como genial oradora ${ }^{27}$ : "el peligro de la patria me arrastra, me transporta sobre mí misma. Levanté mi voz, me arrebaté, mujer débil cual soy, y mis ecos resonaron a través de las preocupaciones". Se ocupó de cuanto llamaba su atención. Fue la primera en concebir el plan de contribución patriótica para paliar el déficit en que se hallaba sumida Francia por los desmedidos gastos de la monarquía. Sus propias ofrendas hicieron ejemplo de su palabra. Pidió la supresión por seis meses de los Estados Generales para que se suavizara la severidad del poder. Propuso un regente, invitando a quien se estimase digno de tal cargo a proponerse. Formuló la abolición de la mendicidad, la creación de talleres públicos para paliar la miseria de los obreros sin trabajo, y otras medidas recibidas con aplauso, sorpresa, disgusto o indiferencia

El ritmo y la osadía que fueron tomando sus palabras llevaron a sus amigos a advertirla y animarla a ser más comedida. Mercier, diputado de la Convención, fue uno de ellos. Olympe se defendió en este caso diciendo: “Me he lanzado a la peligrosa carrera donde han tropezado tantos grandes hombres, Mercier atemorizóse por mí, y me aconsejó que retrocediera y me retirase cuando aún era tiempo, yo, altiva y osada como Rousseau, no quise desistir de mi empeño".

Escribió cartas al rey, a la reina, y a quienes consideró podían influir para movilizar hacia lo que ella consideraba la verdad y la justicia. Con ocasión de un acto en honor a un individuo asesinado en trágicas circunstancias, dirigió a sus conciudadanas una misiva en la que les exhortaba a tomar conciencia de los nuevos aires de libertad que ella respiraba con fruición, y a unirse como grupo para conseguir los frutos que el tiempo les ofrecía ${ }^{28}$. Su deseo de erigirse en defensora de la causa de las mujeres ya lo

25 Michelet lamenta los pocos datos conservados sobre las circunstancias en que fueron creados y se desarrollaron estos clubes femeninos: “Nous savons peu, malheureusement, l'histoire des sociétés de femmes. C'est dans les mentions accidentelles de journaux, dans les biographies, etc., qu'on en recueille quelques légères traces". (Michelet, 1854).

26 "Chaumette... Cet femme homme, l'impudent Olympe de Gouges, qui fonda la première des sociétès des femmes et marche à la mort par ses crimes! (Lamartine, 1847).

27 “....al oírla tanto en los clubs como en la Asamblea nacional entregarse a su calurosa inspiración, profetizar la emancipación del género humano, proponer, sostener, desarrollar las mociones más atrevidas, y elevarse en algunas ocasiones al nivel de los primeros maestros de la elocuencia, la hubierais creído dotada de nueva vida y de un alma superior a la debilidad de su sexo que hasta entonces no se había ensayado en las altas cuestiones parlamentarias. Más de una vez dejó absortos a los hombres más elocuentes de la época con la riqueza de su imaginación y la fecundidad de sus ideas, y a decir verdad esto es lo que más hizo brillar la celebridad que en poco tiempo adquirió" (Lairtullier, 1841).

28 "Ciudadanas: ¿no fuera ya tiempo de que se hiciera también entre nosotras la revolución? ¿Permanecerán las mujeres eternamente aisladas entre sí? ¿No llegarán jamás a formar cuerpo con la sociedad sino para maldecir a su sexo y causar compasión al otro? ¡Francesas, ya llegó el momento en que hemos de imitar a las romanas y abjurar la aristocracia de la hermosura, que no sirve sino

$10025-362$


había manifestado en el prefacio de una de sus obras, indicando que "tenía intención de retirarse de la sociedad y meditar en soledad un plan que tenía concebido en beneficio de su sexo" 29 . Más tarde, esas aspiraciones se concretaron en su "Declaración de los derechos de la mujer y la ciudadana" que, en 1791 dirigió a María Antonieta solicitando su solidaridad y apoyo ${ }^{30}$. La audacia extrema de Olympe fue haciéndola cada vez más molesta a ojos de los dirigentes surgidos de la Revolución. Enemiga de los jacobinos y los franciscanos, no se sustraía a lanzar sus opiniones más corrosivas sobre ellos, aun siendo consciente de que podía cavarse su propia tumba ${ }^{31}$. Su desgracia comenzó a fraguarse cuando defendió la figura del último de los $\mathrm{Capetos}^{32}$. Su idea era establecer la diferencia entre el hombre y la función, pero no fue comprendida. Recomendó abiertamente su destierro en lugar de su muerte, e instó la celebración de un Plebiscito Nacional para elegir entre gobierno republicano unitario, federación o monarquía, sin percatarse de las enemistades que tales peticiones podían acarrearle.

Se perdió definitivamente cuando, sin poner freno a su lengua, arremetió contra quienes dictaban los destinos franceses. Pregonó sin medida su odio a Marat ${ }^{33}$, a quien tachó de "engendro humano sin físico ni atributos morales de hombre", y a

para alentar la de los enemigos de la patria!... Es preciso que las mujeres tímidas se alienten, que las mujeres ilustradas estimulen a sus hijas y que todas vengan a cumplir el voto que en nombre de las mujeres he hecho a la memoria del Corregidor de Estampa...!" (Lairtullier, 1841).

29 “No obstante sus defectos, conozco que un día puede mejorar de condición, y que está pronto a sacudir la coyunda de ominosa esclavitud. El sexo conoce con dolor que su gloria no tiene imperio sino sobre las debilidades de los hombres cuyos deseos pronto van seguidos por el menosprecio... Se está preparando una revolución que elevará el alma y el entendimiento de uno y otro sexo y vendrá tiempo en que ambos a dos coadyuvarán al bien general" (Lairtullier, 1841).

30 “...Sólo incumbe a aquella que el azar ha elevado a una posición eminente dar importancia a progreso de los derechos de la mujer y acelerar su triunfo...esta obra no se llevará a cabo hasta que todas las mujeres estén convencidas de su deplorable destino y de los derechos que han perdido en la sociedad..." (Alonso, I., y Belinchón, M., 1989)

31 "Informe e ilegal conjunto; déspotas, perturbadores de las leyes y del reposo público, ya no sois hombres, ya dejáis de ser franceses. Ocultaos sol jacobino y luna franciscana; vuestros rayos funesto impiden la salida del astro constitucional cuyos resplandores han de poner a cubierto indistintamente a todos los ciudadanos de los abusos de la tirania y de la esclavitud. No ignoro que con este lenguaje concito contra mis dos ejércitos enemigos, pero, ¿qué importa el sacrificio de mi vida? Una débil mujer, cuando se trata de salvar la patria, no se deja afectar por otro interés alguno" (Lairtullie 1841).

32 “Olimpia disgustó a algunos hombres de la montaña con sus tendencias monárquicas (pidió el destierro para el rey, pero no su muerte). Olimpia se defendió. Habló de sus sacrificios en pro de la causa pública, que había extenuado su salud y su fortuna, "el haber sido ella un gran hombre a tiempo en que Marat, Robespierre y Bourdon aún no eran más que viles esclavos y unos insectos encenagados en el lodazal de la corrupción" (Lairtullier, 1841).

33 "Ese miserable Marat, que acaba de salir triunfante de su cueva, cargado con la ignominia general, y que vuelve a sacuir en sus escritos pestilenciales las antorchas del infierno, ese miserable Marta, repito, no es más que un figurón de este proyecto insensato; pero no tardará este moderno Nostradamus en zambullirse otra vez en su caverna subterránea" (Lairtullier, 1841).
Robespierre ${ }^{34}$, a quién calificó de "animal anfibio" y le sugirió que se sumergiera en el Sena. En el colmo de su temeridad, publicó un libelo, ocultando por primera vez su nombre ${ }^{35}$, en el que acusó a Robespierre de querer usurpar el poder e instalarlo sobre sus innumerables crímenes. Consciente de que nada podía ya salvarla dirigió un nuevo folleto a Marat y Robespierre en el que "derramó a manos llenas lo más acervo y violento que puede producir el ultraje".

Sin demora, fue arrestada el 25 de julio de 1793, conducida a L'Abbaye y luego a la Petit-Force. En agosto se instruyó su proceso. Demostró gran fortaleza y asumió su propia defensa, aunque tuvo momentos de flaqueza al inventar un embarazo ficticio. Subió animosa al carro que la llevaría al cadalso e hizo bromas sobre su aspecto. Antes de morir guillotinada, el 4 de noviembre de 1793, pidió venganza de su sangre al pueblo. Quince días antes había sido ajusticiada María Antonieta y cinco días después lo fue Mme. Rolland. Aunque disponemos de testimonios que nos brindan la verdadera talla de esta gran mujer ${ }^{36}$, otros, como el aparecido en "Le Moniteur", intentaron aniquilar su imagen, ofreciendo de ella una visión denigratoria que dejó estigmatizado su nombre $^{37}$. No obstante, el deseo de sumirla en el oprobio, presentándola como pérfida, conspiradora y, sobre todo, como transgresora social, resultó fallido. Rescatada para la historia, aparece a nuestros ojos como la persona que sintetizó el alma de las mujeres revolucionarias, con su obra “Declaración de los derechos de la mujer y la ciudadana"38.

34 “Adiós Bourdon, Marat, y toda la chusma de zánganos, ya quedáis libres de un centinela vigilante, cuya alma virtuosa, no menos libre que altiva, censuraba la corrupción de la vuestra: revolved la Francia como queráis; dilapidad sus rentas, provocad el robo y el asesinato; repartíos los empleo sustituid a las virtudes y los talentos por los vicios, la insolencia y la nulidad. Tú, Robespierre, iahl, si esto es cierto infelices de vosotros! Pues cuando un malvado obra bien es que prepara ¿ah., si esto es cich $y$ mucho me temo que este recambio de tu ambición no nos de pronto une prepara muy lúgubre ¡Mira cuan diferentes son nuestgras almas! La mía es verdaderamente republicana, la (thya no lo fue jamás" (Lairtullier, 1841).

35 Firmó como Polinia (anagrama de Olimpia) y añadió: “Soy un animal sin par, no soy hombre, ni mujer, tengo el valor del uno y a veces la fragilidad de la otra. Hállense en mis discursos todas las virtudes de la igualdad, en mi fisonomía los rasgos de la libertad, y en mi nombre algo de celestial". Luego, en el folleto que dio respuesta a la justificación de Robespierre, asumiría la autoría diciendo: "Soy yo, Maximiliano, yo soy el autor de tu pronóstico; yo, repito, Olimpia de Gouges, más hombre que mujer" (Lairtullier, 1841)

36 "Mme. De Gouges fue sin contradicción una de las mujeres más despejadas, elocuentes y animosas que haya producido Francia... noble y generosa y en algunas circunstancias tan sublime. Su cabeza la arrastraba más velozmente que su corazón... En ella no hay que buscar sino espontaneidad arrebato... Hubierase dicho que en su alma habían fermentando mil gérmenes de republicanismo y libertad para estallar y hacer explosión al mismo tiempo que amanecía el gran día en el horizonte político de la patria" (Lairtullier, 1841).

37 “Olympe de Gouges, dotada de una imaginación exaltada tomó su desvarío por una inspiración que le dictaba la naturaleza. Empezó por disparatar y acabó haciendo suyo el proyecto de aquellos seres pérfidos que pretendían dividir el país; quiso ser hombre de estado y parece como si la ley hubiese castigado a dicha conspiradora por haberse olvidado de cuáles son las virtudes de su sexo (Alonso, I., y Belinchón, M., 1989).

38 He seguido para su análisis el texto que aparece en la obra (Alonso, I., y Belinchón, M., 1989). 
Este texto delata que su autora no era una ignorante, pues, como sugiere Lairtullier "semejante estilo y un tono tan elevado no son por cierto de una mujer vulgar; y no puede dejar de notarse que más de una vez su lenguaje es de legislador". Consta dicho texto de una introducción, un preámbulo, diecisiete artículos y un epílogo. Precede al preámbulo una petición: "Para ser decretado por la Asamblea Nacional en sus últimas sesiones o en la próxima legislatura". Va dirigido al "Hombre" que, presentado como paradigma de lo humano, se había olvidado que coexistía junto a otro sexo dotado de facultades intelectivas y que deseaba "gozar de la revolución y reclamar sus derechos a la igualdad". Puso la solicitud de reconocimiento de esos derechos legítimos y usurpados en boca de las madres, hijas, hermanas, representantes de la Nación... por considerar que la ignorancia, el olvido o el desprecio a los derechos de la mujer son las únicas causas de los males públicos y de la corrupción de los gobiernos, han resuelto exponer en una declaración solemne los derechos naturales, inalienables y sagrados de la mujer...".

Se deduce de ello que Olympe, como tantas otras mujeres, no se sentía incluida en la "Declaración de los derechos del hombre y del ciudadano", publicada por la Asamblea el 26 de agosto de 1789. Tras el largo preámbulo se desgranan uno tras otro los artículos que recogen el anhelo de Olympe de sentirse incluida dentro de un ideario revolucionario que, intrínsecamente, y ya desde su propia formulación, excluía al sexo femenino. Así, declara: “La mujer nace libre y permanece igual al hombre en derechos" (Art. I). "El objetivo de toda asociación política es la conservación de los derechos naturales e imprescriptibles de la mujer y el hombre" (Art. II). "El principio de toda soberanía reside esencialmente en la Nación que no es más que la reunión de la mujer y el hombre...” (Art. III). “...el ejercicio de los derechos naturales de la mujer sólo tiene por límites la tiranía perpetua que el hombre le opone; estos límites deben ser corregidos por las leyes de la naturaleza y la razón" (Art. IV).

Reclama el derecho al sufragio universal femenino en el artículo VI, al igual que el de ser elegible a todos los cargos, según capacidades, única limitación para acceder a ellos. Esta idea la reitera en el artículo XIII; mientras, en el XV exige la participación de las mujeres en el control del gasto público, argumentando que ellas también contribuyen al sostenimiento de la Administración. Congruente con sus postulados, en el artículo IX, opina que el peso de la ley debía caer, con todo rigor, sobre la delincuente.

Más conocido es, quizá, el artículo $X$, aquél en el que reivindica la libertad de expresión, el derecho a subir a la tribuna de igual modo que puede subir al cadalso. Justifica la necesidad de que las mujeres participen en la elaboración de las leyes que van a regirlas, porque "la constitución es nula si la mayoría de los individuos que componen la Nación no ha cooperado en su redacción" (Art. XVI). Solicita el derecho a la propiedad, reconocida para los varones, sin que nadie tenga el poder de alienar o privar de él a las mujeres, salvo "por necesidad pública" (Art. XVII). En el epílogo expresa claramente cómo la Revolución y los revolucionarios habían usado la fuerza femenina para después relegarla: "Mujer, despierta; el rebato de la razón se hace oír en todo el universo; reconoce tus derechos. El potente imperio de la naturaleza ha dejado de estar rodeado de prejuicios, fanatismo, superstición y mentira. La antorcha de la verdad ha disipado todas las nubes de la necedad y la usurpación. El hombre esclavo ha redoblado sus fuerzas y ha necesitado apelar a las tuyas para romper sus cadenas. Pero una vez en libertad, ha sido injusto con su compañera... ¿Qué ventajas habéis obtenido de la Revolución?".

Estas palabras sirven para efectuar el balance de los logros femeninos tras aquellos momentos decisivos. Podría afirmarse que fue negativo, pues, a nivel ideológico, como se ha indicado, triunfará el discurso de Rousseau; a nivel jurídico las mujeres vieron recortados todos sus derechos. Y, finalmente, en la recién saboreada actividad pública se estableció la tan típica, tópica y excluyente división mujer pública/hombre público harto conocida. El año de la muerte de Olympe fueron cerrados los clubes femeninos. Este acto se vio precedido en la Asamblea por un discurso de los ciudadanos Chaumette y Amard, quienes dictaminaron sobre la necesidad de hacer volver a las mujeres al lugar de donde nunca debieron haber salido ${ }^{39}$.

Con el dolor de la guillotina, la cárcel, el destierro, el manicomio o el olvido hubieron de cargar las mujeres que se destacaron en la lucha por la libertad y la igualdad. Todo podía resumirse en un axioma que, magníficamente expresado por Chaumette, decía: "las mujeres no son algo, más que cuando los hombres no son nada" (Lamartine, 1847). urante muchos años la valerosa lucha de tantísimas mujeres quedó perdida en un rincón, junto a unas aspiraciones legítimas cimentadas sobre los principios de la Ilustración. Tal vez, como indica Isabel Cristina Cardona,

El mayor obstáculo para el reconocimiento de la lucha que a través de la historia han protagonizado las mujeres sea la falta de memoria, la incansable insistencia de la humanidad por borrar esa parte femenina de la historia... La historia nos ha enseñado que el mundo ha sido imaginado y creado por los hombres, de nosotras depende ahora descubrir el rostro femenino de la historia (Cardona, I.S., 2009).

\section{REFERENCIAS BibLIOgRáficas}

Alonso, I.-Belinchón, M. (ed.), "1789-1793 La voz de las mujeres en la Revolución francesa", Cuadernos de quejas y otros textos, Barcelona, LaSal, 1989.

39 “... ¿ ¿desde cuándo está permitido a las mujeres abjurar de su sexo, abandonar los piadosos cuidados de la casa y las cunas de sus hijos, para ir a la plaza pública, a la tribuna de las arengas, a la barra del senado, a las filas de nuestros ejércitos, usurpando derechos que la naturaleza ha concedido" (Michelet, 1854).

Revista Internacional de Culturas y Literaturas, abril 2012 
Cardona, I.S., "Las furias de la guillotina: tras el rostro femenino de la Revolución Francesa”, Agenda Cultural Alma Mater, núm. 160, Universidad de Antioquia, 2009.

Code civil des Français. Edition Originale et seule Officielle, Paris, Impremerie de la République, 1804.

Duhet, , P-M., Las mujeres y la Revolución, 1789-1794, Barcelona, Edic. Península, 1974.

Guerin, D., La lucha de clases en el apogeo de la Revolución Francesa, 1793-1795, Madrid, Alianza Editorial, 1974.

Hirschbberger, J., Historia de la Filosofía. Edad Moderna - Edad Contemporánea, Tomo II, Barcelona, Herder, 1978.

Lamartine, A. Histoire des Girondines, Tome Septième, Bruxelles, Meline, Cans et Compagnie, 1847.

Lairtullier, , E., Las Mujeres célebres en Francia desde 1789 hasta 1795 y su influjo en la Revolución, Barcelona, Librería de Juan Oliveres, 1844.

Lenotre, G., La petite Histoire. La Revolution par ceux qui l'ont vue, Paris, Grasset, 1934.

Lefebvre, G., El nacimiento de la Historiografía moderna, Barcelona, Edic. Martínez Roca, S.A., 1985.

Michelet, J., Les femmes de la Révolution, 1954, http://www.inlibroveritas.net/lire/oeuvre11774.html

Márquez, J., "Igualdad y modernidad: Alexis de Tocqueville y Max Weber”, Razón Cínica 2.0, núm. 1, abril 2010, http://www.politicas.unam.mx/razoncinica/n1a3.html

Puleo, A., Concorcet, De Gouges, De Lambert y otros. La Ilustración olvidada. La polémica de los sexos en el s. XVIII, Barcelona, Anthropos, 1993.

Rousseau, J. J. , Emilio o de la Educación, Barcelona, Fontanella, 1973.

Scott, J. W., "French Feminists and the Rights of 'Man': Olympe de Gouges's Declarations" History Workshop, 1989, No. 28: 1-21.

Sledziewski, , E. G., “Revolución Francesa. El giro”, en Duby, G.-Perrot, M. (Dirs.): Historia de las mujeres en Occidente, Madrid, Taurus, 1993, Vol. 4.

Tocqueville, A., Inéditos sobre la Revolución, Madrid, Seminarios y Edic. Castilla, 1973. 